NASA Technical Memorandum 107487

AIAA-97-2452

\title{
Modeling Cyclic Phase Change and Energy Storage in Solar Heat Receivers
}

Carsie A. Hall, III, Emmanuel K. Glakpe, and Joseph N. Cannon Howard University

Washington, $D C$

Thomas W. Kerslake

Lewis Research Center

Cleveland, Ohio

Prepared for the

32nd Thermophysics Conference sponsored by the American Institute of Aeronautics and Astronautics Atlanta, Georgia, June 23-25, 1997

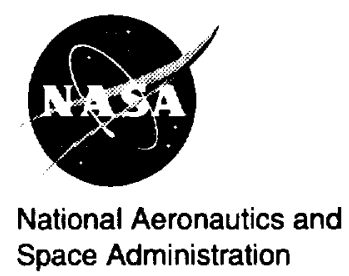




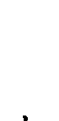




\title{
MODELING CYCLIC PHASE CHANGE AND ENERGY STORAGE IN SOLAR HEAT RECEIVERS
}

\author{
Carsie A. Hall, III*, Emmanuel K. Glakpe $\dagger$, and Joseph N. Cannon $\ddagger$ \\ School of Engineering, Howard University, Washington, D.C. 20059 \\ and \\ Thomas W. Kerslake $\S$ \\ NASA Lewis Research Center, Cleveland, Ohio 44135
}

\begin{abstract}
Numerical results pertaining to cyclic melting and freezing of an encapsulated phase change material (PCM), integrated into a solar heat receiver, have been reported. The cyclic nature of the present melt/freeze problem is relevant to latent heat thermal energy storage (LHTES) systems used to power solar Brayton engines in microgravity environments. Specifically, a physical and numerical model of the solar heat receiver component of NASA Lewis Research Center's Ground Test Demonstration (GTD) project was developed and results compared with available experimental data. Multi-conjugate effects such as the convective fluid flow of a low-Prandtl-number fluid, coupled with thermal conduction in the phase change material, containment tube and working fluid conduit were accounted for in the model. A single-band thermal radiation model was also included to quantify reradiative energy exchange inside the receiver and losses through the aperture. The eutectic $\mathrm{LiF}-\mathrm{CaF}_{2}$ was used as the phase change material (PCM) and a mixture of $\mathrm{He} / \mathrm{Xe}$ was used as the working fluid coolant. A modified version of the computer code HOTTube was used to generate results for comparisons with GTD data for both the subcooled and two-phase regimes. While qualitative trends were in close agreement for the balanced orbit modes, excellent quantitative agreement was observed for steady-state modes.
\end{abstract}

\section{Nomenclature}

$\begin{array}{ll}\mathrm{A} & =\text { solid cross-sectional area } \\ \mathrm{c} & =\text { specific heat of solid regions } \\ \mathrm{c}_{\mathrm{p}} & =\text { specific heat of working fluid } \\ \mathrm{f} & =\text { geometric view factor } \\ \mathrm{h}, \mathrm{h}^{*} & =\text { specific enthalpy, heat transfer coefficient } \\ \mathrm{h}_{\mathrm{sf}} & =\text { PCM latent heat of fusion } \\ \mathrm{L} & =\text { active tube or cavity length } \\ \dot{m} & =\text { mass flow rate } \\ \mathrm{M} & =\text { total number of axial nodes along tube } \\ \vec{n} & =\text { outer unit normal } \\ \mathrm{N} & =\text { total number of tubes in receiver } \\ \mathrm{P} & =\text { wetted perimeter } \\ \dot{q^{\prime \prime}} & =\text { heat flux } \\ \dot{Q} & =\text { heat transfer rate } \\ \mathrm{r} & =\text { radial location }\end{array}$

Copyright (c) 1997 by the American Institute of Aeronautics and Astronautics, Inc. All rights reserved.

*Doctoral Candidate, Department of Mechanical Engineering. Student Member AIAA.

$\dagger$ Professor, Department of Mechanical Engineering. Member AIAA.

‡ Professor, Department of Chemical Engineering.

§Power Systems Engineer.
$\mathrm{R}=$ thermal resistance

S* = geometric shape factor

$\mathrm{t}=\mathrm{time}$

$\mathrm{T}=$ temperature

$\vec{U} \quad=$ velocity vector

$\mathrm{W} \quad=$ width of $\mathrm{PCM}$ region

$\mathrm{X}=\mathrm{PCM}$ liquid fraction

$\mathrm{Z}=$ axial location

$\kappa \quad=$ shell loss function

$\theta \quad=$ dimensionless working fluid temperature

$\rho \quad=$ density

$\sigma \quad=$ Stefan-Boltzmann constant

$\omega=$ turboalternator $\mathrm{TAC}$ speed

\section{Subscripts}

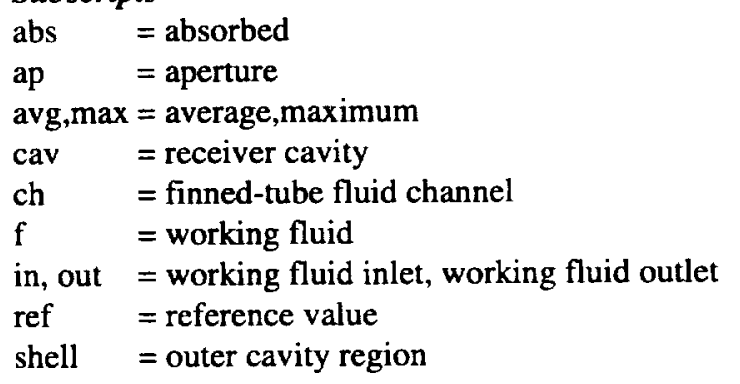

\section{Superscripts \\ $\mathrm{n}=$ previous time level \\ $\mathrm{n}+1=$ current time level}




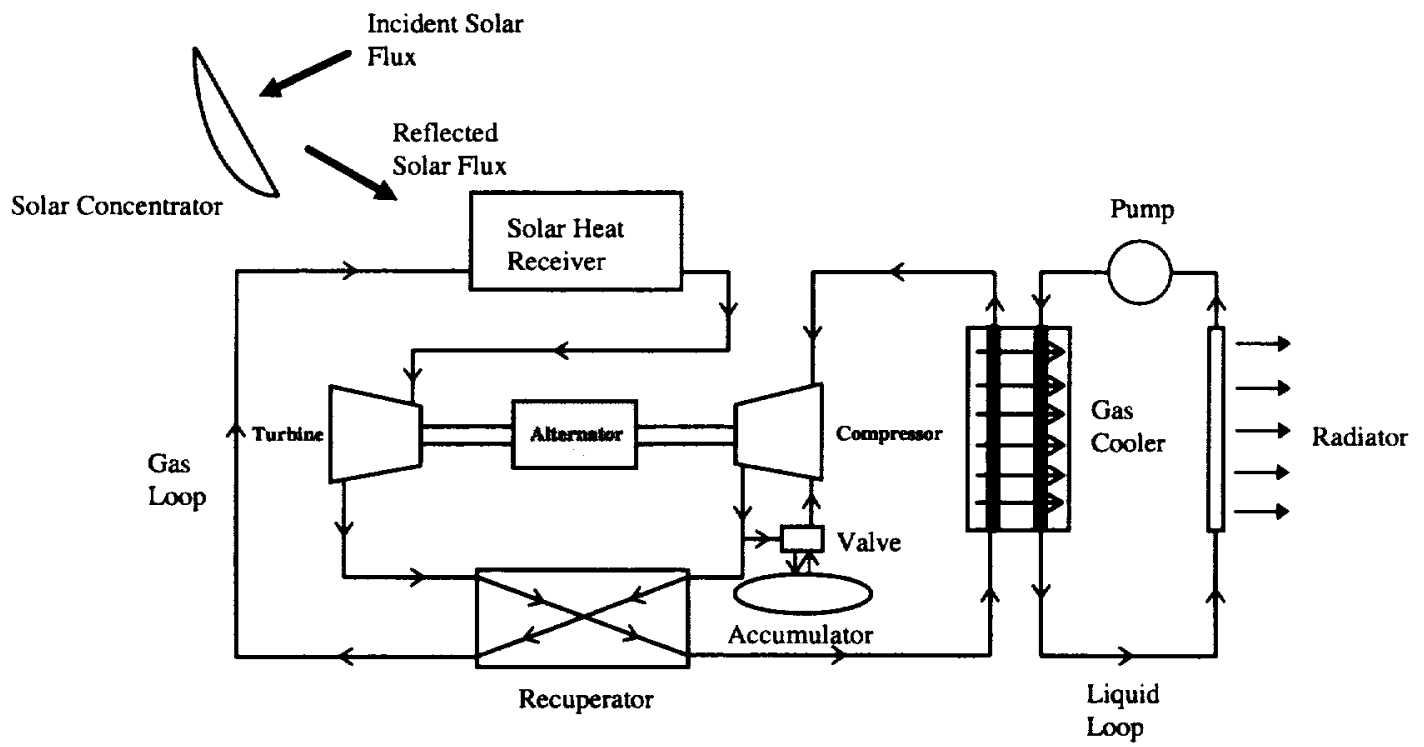

Fig. 1 Thermodynamic cycle for closed Brayton engine integrated with solar heat receiver.

\section{Introduction}

$\mathbf{T}$ THE intermittent nature of solar energy availability for Earth-orbit applications presents a particular challenge for space power management schemes during traversal into Earth's shadow (eclipse phase). One alternative to photovoltaics with battery storage is solar dynamics with latent heat thermal energy storage (LHTES) via solar heat receivers. Solar heat receivers are very instrumental components in the production of electric power via solar dynamic power systems (SDPSs). In a typical operation, the SDPS uses: 1) a concentrator to collect and focus the incident energy onto the aperture plane of a central receiver, 2) a central receiver to collect and distribute, with minimal losses, the reflected energy from the concentrator, 3 ) working fluid tubes aligned along the periphery of the receiver to absorb the distributed energy as heat, thus, raising the temperature of the working fluid (typically a lowPrandtl-number fluid) flowing through the tubes, 4) a turbine to expand the high temperature working fluid to produce mechanical work via a rotating shaft, 5) a compressor to circulate the working fluid through the working fluid tubes, and 6) an alternator to convert mechanical shaft motion into electric power. Often times a recuperator is added to increase the thermal efficiency of the thermodynamic cycle (typically a closed Brayton cycle as depicted in Fig. 1).

Solar heat receivers employing encapsulated phase change materials (PCMs) have the advantage over sensible heat receivers of requiring less mass while producing higher energy storage densities. This, in turn, makes them ideal candidates for energy storage in the space environment where temperatures are sufficiently high and PCMs with high latent heats of fusion become indispensable. In this regard, phase change salts such as the eutectic mixture $\mathrm{LiF}-\mathrm{CaF}_{2}$, which has a melting point of $1413^{\circ} \mathrm{F}\left(767^{\circ} \mathrm{C}\right)$ and a heat of fusion of $340 \mathrm{Btu} / \mathrm{b}_{\mathrm{m}}(789 \mathrm{~kJ} / \mathrm{kg})$, lends itself as a favorable candidate for latent heat thermal energy storage (LHTES) in the harsh space environment.

Investigations on modeling and testing solar heat receivers and/or their subcomponents employing phase change storage have appeared in the literature. Strumpf and Coombs ${ }^{1}$ conducted an experimental investigation to quantify the thermal performance of the receiver tube section of a solar heat receiver subject to a simulated solar flux (using a heater panel with heater wires embedded in an insulating material), cycled to approximate orbital conditions using air as the Brayton engine working fluid. Sedgwick ${ }^{2}$ employed two receiver thermal models which use an implicit finitedifference scheme to solve the resulting energy equations. The first one assumes a fixed melt temperature and explicitly tracks the location of the phase (solid/liquid) front. The second algorithm models the latent energy storage as an equivalent sensible energy storage over a small but finite temperature range while updating nodal conductances and thermal capacitances. The computer code RADSIM (Radiation Simulation) was used to calculate solar flux distributions, cavity geometric view factors, and, ultimately, radiation (two-band) heat losses. In the work of Wichner et al. ${ }^{3}$, a finite-difference scheme was 
used for the thermal analysis while a finite element scheme was used for the stress analysis of a single canister model. The effects of solidification front behavior were simulated to include conduction in the solid/liquid phases and canister material, void growth/shrinkage, radiation heat transfer across the void, and convection in the melt due to either the Marangoni flow effect (in microgravity, $\approx 10^{-4} \mathrm{~g}$ ) or buoyancy effects in $1-\mathrm{g}$ environments. A threedimensional model (computer code NORVEX) was formulated by Wilson and Flanery ${ }^{4}$ to analyze the cyclic melting and freezing, fluid flow, and void formation and movement in a hollow metal canister filled with a high temperature PCM.

Kerslake and Ibrahim $^{5}$ developed a two-dimensional, axisymmetric finite-difference model of a Space Station Freedom thermal energy storage canister. A eutectic mixture of $\mathrm{LiF}-\mathrm{CaF}_{2}$ was used as the latent energy storage PCM and the superalloy Haynes 188 was used as its containment material. In their model, the effects of conduction in the canister walls and PCM solid, conduction and free convection in the liquid PCM, and conduction and radiation across a stationary (i.e. no volume change effects) void region filled with low vapor pressure PCM vapor were evaluated. The void was placed adjacent to the canister outer wall.

Drake $^{6}$ developed a three-dimensional model of a PCM canister (LiF PCM with superalloy Haynes 188 containment material) undergoing cyclic melt/freeze cycles with void movement and Marangoni flow effects. The discretized equations were solved via the semiimplicit Crank-Nicholson scheme using a Newton method with Cholesky Factorization. The mushy zone was treated as a porous medium and the Volume of Fluid (VOF) method of Hirt and Nichols ${ }^{7}$ was used to track the void, which was treated as a compressible fluid with zero viscosity. Kerslake $^{8}$ used the computer program NUCAM-2DV to model a two-dimensional, axisymmetric canister using an explicit finite-difference technique. The enthalpy method was employed, and a fixed location, constant void volume with conduction and radiation was modeled. The working fluid used in this model was air.

Strumpf et al. ${ }^{9,10}$ modeled a solar heat receiver using the computer code SOLREC-TSD (Solar ReceiverThermal Storage Device), which is a three-dimensional, transient, finite-element code. This code consists of three sections: 1) a cavity radiation network solver, 2) a detailed finite-element receiver thermal storage model, and 3) a transient heat exchanger fluid solver. Only one-half of the canister was modeled due to imposed symmetry conditions. Sedgwick ${ }^{11}$ reported on the first ever full-size solar dynamic heat receiver, with a thermal output of $102 \mathrm{~kW}$. The receiver was designed to the specifications of the Space Station Freedom. It was tested in a vacuum chamber with liquid nitrogen cooling shrouds and an aperture cold plate to partially simulate the Low-earth orbit (LEO) vacuum environment. Scarda ${ }^{12}$ modeled the NASA Lewis Research Center's TES-1 experiment using a twodimensional SINDA85 model. The TES-1 experiment consisted of a torus-shaped canister, conductor rod, and radiator flare. A heater was used to radiate heat to the outer radius of the canister during the melt cycle. After the PCM (LiF) completely melted, the heater was turned off and the stored latent heat was transferred to the conductor rod where it was eventually radiated to the environment by the TES radiator flare during the freeze cycle. The results of the first flight experiment, the TES Experiment, to study melting and freezing under microgravity conditions were reported by Namkoong et al. ${ }^{13}$ One of the experiments, TES-1, using LiF PCM and superalloy Haynes 188 containment material, was reported to perform flawlessly in its 22 hours of operation. PCM melting was induced by thermal radiation from a heater sleeve surrounding the canister and PCM freezing was induced by shutting the power to the heater and opening the shutter, thus, allowing the stored energy to conduct to the central rod and onto a radiator disc to reject the heat to space. In addition, the computer code TESSIM was used to predict the behavior of the PCM in the canister.

Recently, Shaltens and Mason ${ }^{14}$ reported experimental results on the operational performance of the NASA Lewis Research Center's Solar Dynamic Ground Test Demonstration (GTD) project. Their results are shown for various insolation levels and operating speeds, and in five primary operating modes: 1) orbital startup, 2) transient, 3) balanced orbit, 4) steady-state, and 5) shutdown.

In the present paper, a physical and numerical model is developed to study the cyclic behavior of the solar heat receiver component of the aforementioned GTD system. The numerical results are compared with the experimental results in the balanced orbit mode and steady-state mode for both the subcooled and two-phase regimes. Results are reported in the form of maximum and average canister surface temperatures, receiver gas exit temperatures, and receiver melt fraction, all as a function of insolation level and operating speed (via an equivalent mass flow rate). In this paper, a linear plot of working fluid mass flow rate versus TAC operating speed, provided by Shaltens and Mason, ${ }^{14}$ is used. Predicting the thermal performance is critical in determining the so-called thermal state-of-charge $(S O C)$ of solar heat receivers. Knowledge of the SOC allows for better control strategies relating to power 
management schemes during such operations as peak power demand and emergency shutdowns with subsequent restarts.

\section{Description of the GTD System}

The Ground Test Demonstration (GTD) project is the world's first full scale demonstration of reliable production of electric power via solar dynamics (SD) technology. This government/industry collaboration is carried out in the NASA Lewis Research Center's large thermal/vacuum facility (tank 6). This facility is equipped to provide simulated solar flux in high vacuum, similar to that which is encountered in LEO. The primary objectives of this project are to demonstrate, using flight prototypical components, that system power delivered and system efficiency both fall within design target. Moreover, most of the hardware used in the GTD system are derived from the SD system designed for the Space Station Freedom program.

The $2 \mathrm{~kW}_{\mathrm{e}}$ (nominal) GTD system consists of an offaxis solar concentrator and solar heat receiver with latent heat thermal energy storage (LHTES), both of which are integrated with a closed Brayton engine (power conversion unit or PCU). A more complete description of the GTD system can be found in the paper by Shaltens and Mason. ${ }^{14}$

\section{GTD Solar Heat Receiver Modeling}

\section{Problem Description}

The physical geometry for the present study is depicted in Fig. 2 and the more detailed single-tube model is shown in Fig. 3. It is assumed that each tube in the solar receiver is imparted with the same incident solar flux; therefore, only a single tube needs to be

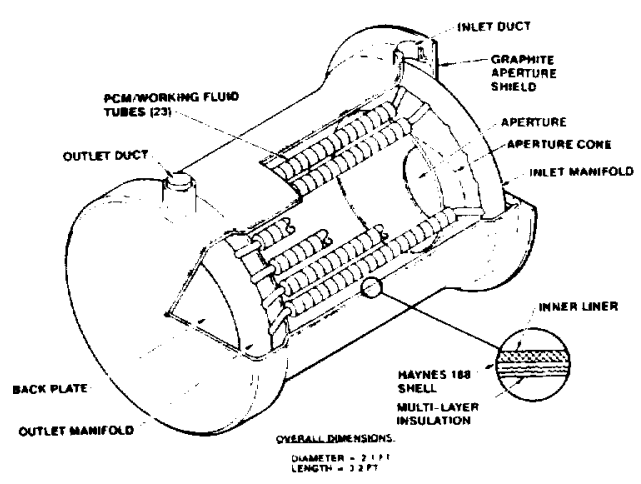

Fig. 2 GTD solar heat receiver design (provided by AlliedSignal Aerospace).

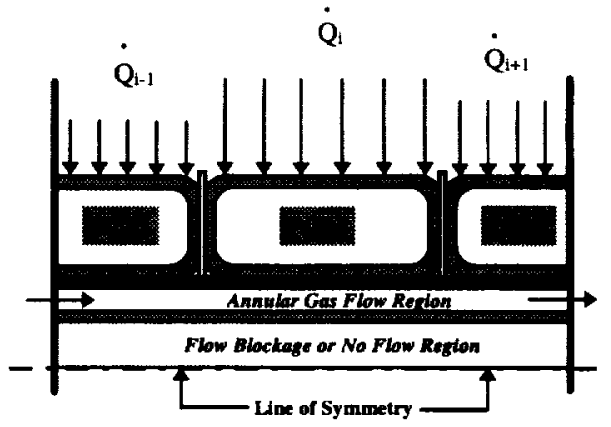

Fig. 3 Schematic of encapsulated PCM tube configuration with annular gas flow.

analyzed, with a subsequent summation over all tubes to quantify the total receiver thermal performance.

\section{GTD Specifications}

The specifications for the solar heat receiver of the GTD system used for modeling, in which the present numerical results reflect, are as follows:

- effective cavity diameter $=1.56 \mathrm{ft}(47.55 \mathrm{~cm})$

- aperture diameter $=7$ in $(17.78 \mathrm{~cm})$

- active tube length $=2 \mathrm{ft}(60.96 \mathrm{~cm})$

- canister outer diameter $=1.78$ in $(4.52 \mathrm{~cm})$

- hydraulic diameter $=0.045$ in $(0.1143 \mathrm{~cm})$

- number of tubes in the receiver $=23$

- number of canisters per tube $=24$

- canister material = superalloy Haynes 188

- $\quad \mathrm{PCM}=\mathrm{LiF}-\mathrm{CaF}_{2}$

- $\quad$ working fluid $=$ helium/xenon $(\mathrm{He} / \mathrm{Xe})$

The GTD design is essentially a scale-down version of the Space Station Freedom SDPS, which was designed to yield a nominal alternator power output of $35 \mathrm{~kW}_{\mathrm{e}}$.

\section{Governing Equations}

The generalized integral equation governing the evolution of the enthalpy per unit mass for a region (denoted as $\mathrm{k}$ ) is given by

$$
\frac{\partial}{\partial t} \int_{V_{k}} \rho_{k} h_{k} d V_{k}=-\int_{S_{k}} \rho_{k} h_{k} \vec{U}_{k} \cdot \vec{n}_{k} d S_{k}-\int_{S_{k}} \vec{q}^{\prime \prime} \cdot \vec{n}_{k} d S_{k}
$$

which is coupled to the temperature of the kth region by the general equation of state

$$
h_{k}-h_{r e f}=\int_{T_{r e f}}^{T_{k}} c_{k}\left(T_{k}{ }^{\prime}\right) d T_{k}{ }^{\prime} \cong c_{k}\left(T_{k}-T_{\text {ref }}\right)
$$


for constant $c_{k}$ where each of the $k$ regions is identified as follows: $k=1$ (outer canister region); $k=2$ (PCM region); $k=3$ (inner canister region); $k=4$ (working fluid tube region); $k=5$ (working fluid region). In the solid regions and liquid $\mathrm{PCM}$ region (due to the assumption of no convective motion), $\vec{U}_{k}=\overrightarrow{0}$.

\section{Discrete Representations}

It should be stated at the outset that the containment canister outer and inner regions, along with the working fluid tube region, are all considered radially lumped. As a result, the radial index $\mathrm{j}$ corresponding to the representative temperatures of those regions are $\mathrm{j}=1$, $\mathrm{j}=\mathrm{jmax}-1$, and $\mathrm{j}=\mathrm{jmax}$ for the outer canister, inner canister, and working fluid tube regions, respectively. The remaining PCM region is divided into jmax-3 nodes, for each ith axial location along the tube.

Applying Eq. 1 to a control volume at the ith outer canister location $(k=1)$ along the tube results in

$$
(\rho A)_{1} \Delta z\left(\frac{h_{1_{i, j}}^{n+1}-h_{1_{i, j}}^{n}}{\Delta t}\right)=\dot{Q}_{a b s_{i}}^{n}-\left(\frac{T_{2_{i, j+1}}^{n}-T_{1_{i, j}}^{n}}{R_{1_{i, j+1}}}\right)
$$

where $\mathrm{i}$ is the discrete index corresponding to the axial direction $(i=1,2, \ldots \ldots, M) ; j$ is the discrete index corresponding to the radial direction $(j=1,2, \ldots \ldots, j \max )$; $\mathrm{n}$ is the discrete index for the previous time level and $\mathrm{n}+1$ is the discrete index for the current time level. For the PCM region $(k=2)$, the discrete equation is expressed as

$$
(\rho A)_{2}\left(\frac{h_{i_{i, j}}^{n+1}-h_{2_{, j, j}}^{n}}{\Delta t}\right)=\left(\frac{T_{2_{i, j+1}}^{n}-T_{2_{i, j}}^{n}}{R_{2_{i, j+1}}}\right)-\left(\frac{T_{2_{i, j, 1}}^{n}-T_{2_{i, j}}^{n}}{R_{2_{i, j, 1}}}\right)
$$

which is valid in the region $2 \leq \mathrm{j} \leq \mathrm{jmax}-2$. Another important consideration is that since the zero reference level for the PCM enthalpy per unit mass is in the subcooled regime, and is somewhat arbitrary, a "flag" based on temperature is used to indicate proximity to the melting point. As a result, an additional equation governing the fraction of PCM mass in the liquid phase is given by

$$
\frac{m_{i, j} h_{s f}}{W}\left(\frac{X_{i, j}^{n+1}-X_{i, j}^{n}}{\Delta t}\right)=\left(\frac{T_{2_{i, j+1}}^{n}-T_{i_{i, j}}^{n}}{R_{2_{i, j+1}}}\right)-\left(\frac{T_{2_{i, j-1}}^{n}-T_{i_{i, j}}^{n}}{R_{2_{i, j-1}}}\right)
$$

where the liquid fraction for the ith axial canister location and $\mathrm{jth}$ node is in the range $0 \leq \mathrm{X}_{\mathrm{i}, \mathrm{j}} \leq 1$. This scheme can be considered a hybrid between the enthalpy method and the front tracking method, since the interface is not tracked explicitly but an additional equation is used. Furthermore, the discrete equations governing the evolution of enthalpy per unit mass for the canister inner region $(k=3)$ and working fluid tube region $(k=4)$ are derived as

$$
\begin{array}{r}
(\rho A)_{3}\left(\frac{h_{i_{i, j}}^{n+1}-h_{3_{i, j}}^{n}}{\Delta t}\right)=\left(\frac{T_{4_{i, j+1}}^{n}-T_{3_{i, j}}^{n}}{R_{3_{i, j+1}}}\right)-\left(\frac{T_{2_{i, j},}^{n}-T_{3_{i, j}}^{n}}{R_{3_{i, j}}}\right) \\
(\rho A)_{4} \Delta z\left(\frac{h_{4_{i, j}}^{n+1}-h_{4_{i, j}}^{n}}{\Delta t}\right)=\dot{Q}_{f_{i}}^{n}-\left(\frac{T_{3_{i, j-1}}^{n}-T_{4_{i, j}}^{n}}{R_{4_{i, j-1}}}\right) \\
+\left(\frac{T_{4_{i+1, j}}^{n}-T_{4_{i, j}}^{n}}{R_{4_{i+1, j}}}\right)+\left(\frac{T_{4_{i-1, j}}^{n}-T_{4_{i, j}}^{n}}{R_{4_{i-1, j}}}\right)
\end{array}
$$

For the working fluid region $(k=5)$, a $1-D$, quasi-steady model for the axial transport of enthalpy per unit mass is used. A modified version of the closed-form solution given by (for an isothermal wall condition)

$$
\theta(z)=\frac{T_{s}-T_{f}}{T_{s}-T_{i n}}=e^{-\left(\frac{P h^{*} z}{m c_{p}}\right)}
$$

is written for the present configuration as

$$
\theta_{i}^{n+1}=\frac{T_{s_{i}}^{n+1}-T_{f_{i}}^{n+1}}{T_{s_{i}}^{n+1}-T_{i n_{i}}^{n+1}}=e^{-\left(\frac{P_{c h} s^{*} h^{*} \Delta z}{m_{c h} c_{p}}\right)}
$$

where $P_{c h}$ is the channel wetted perimeter, $m_{c h}$ is the channel mass flow rate, and $S^{*}$ is a geometric shape factor (estimated to be in the range $1 \leq S^{*} \leq 1.2$ ), used to account for the degree of departure from triangularity of the finned-tube cross-section. Finally, the net rate of axially convected enthalpy, used in Eq. 7, is expressed

as

$$
\dot{Q}_{f_{i}}^{n}=\dot{m} c_{p}\left(T_{f_{i-1}}^{n}-T_{f_{i}}^{n}\right)
$$

\section{Thermal Radiation Model}

An energy balance on the ith node results in the following equation governing the net rate of energy absorbed at the ith node:

$$
\dot{Q}_{a b s_{i}}=\dot{Q}_{i}+\dot{Q}_{R_{i}}-\dot{Q}_{a p_{i}}-\dot{Q}_{\text {shell }_{i}}
$$

where for $i=1,2, \ldots \ldots \ldots . M$ 


$$
\begin{aligned}
& \dot{Q}_{R_{i}}=\frac{A_{i}}{N} \sigma \sum_{j=1}^{M+2} f_{i-j}\left(T_{j}^{4}-T_{i}^{4}\right) \\
& \dot{Q}_{a p_{i}}=\frac{A_{i}}{N} \sigma f_{i-a p}\left(T_{i}^{4}-T_{a p}^{4}\right)
\end{aligned}
$$

and the receiver shell loss per node is given by

$$
\dot{Q}_{\text {shell }_{i}}=\frac{\kappa\left(T_{\text {avg }}\right)}{N M}
$$

In this equation, the function $\kappa\left(T_{\text {avg }}\right)$ is recommended by Ensworth et al. ${ }^{16}$ to be

$$
\kappa\left(T_{\text {avg }}\right)=b\left(\frac{T_{\text {avg }}}{T_{\text {ref }}}\right)^{4}
$$

where $b=0.82, T_{\text {ref }}=1860 \mathrm{R}(1033 \mathrm{~K})$, and $T_{\text {avg }}$ is the instantaneous, spatially-averaged canister outer surface temperature, given by

$$
T_{\text {avg }}(t)=\frac{1}{L_{\text {cav }}} \int_{0}^{L_{\text {cuv }}} T_{1}(z, t) d z
$$

\section{Modified HOTTube Code}

The numerical results presented in this present paper were generated using a modified version of the computer code HOTTube, which is a transient, timeexplicit, axisymmetric total receiver thermal analysis code. HOTTube was initially developed by AlliedSignal Aerospace for the Space Station Freedom solar heat receiver. The PCM melting and freezing processes are modeled using a hybrid enthalpy/temperature formulation with mushy zone prediction capability. Therefore, explicit interface tracking is not performed. The use of adiabatic spacers between canisters permit thermal decoupling axially in the containment tube and PCM but with twodimensional thermal conduction in the working fluid conduit. As a result, a continuous interface along the axial direction does not develop. In addition, a onedimensional semi-analytic thermal energy transport model is used for the working fluid coolant, which is justified by the small hydraulic diameter of 0.045 inches for the annular flow region. Temperature-dependent thermophysical properties are taken into account for the working fluid coolant. Finally, a perfect optics thermal radiation model is assumed for the reradiative energy transport to and from the containment canister outer surface and receiver backwall. In addition, radiation losses through the aperture as well as conduction losses through the receiver shell are taken into account.

The physical domain is discretized into a 24 (axial) $x$ 15 (radial) grid scheme and a time step of $60 \mathrm{~ms}$ is used, which is below that which is required for numerical stability. These are used after achieving gridindependence. The receiver backwall is modeled using a single node (isothermal but time-varying), as are the aperture and aperture plate. Since the incident flux distribution is considered the same for all tubes in the receiver, the radiative flux model includes the backwall, 24 axial rings, the aperture and aperture plate, each of which are isothermal but time-varying. After all of the geometric view factors are calculated, reradiative energies from ring-to-ring, ring-to-backwall, ring-toaperture plate, and vice versa, are evaluated. Finally, the net absorbed energy per node is calculated, which is the difference between the energy incident upon that node, energy reradiated from other nodes including the backwall and aperture plate, and energy lost from the node due to infrared emission back out through the aperture. This net absorbed energy is used to drive the heat transfer and, ultimately, the phase change process.

The temperature distributions in the containment tube walls, PCM, and working fluid conduit are determined from finite volume representations of the enthalpy form of the energy equation. Convective effects due to buoyancy, thermo-capillarity, soluto-capillarity, or volume change (void formation) are not included in the present model. This is partially justified by the use of adiabatic spacers, which will lead to substantially reduced hydrostatic potential in each canister since the liquid formed in each canister will be confined and not allowed to interact (neither thermally nor hydrodynamically) with liquid formed in the other canisters.

The numerical results from HOTTube, which were generated on Howard University's IBM ES 9000 mainframe computer, required approximately twenty CPU minutes per cycle.

\section{Results and Discussion}

The results presented in this section pertain to a maximum insolation orbit for the orbital altitude corresponding to 93 minutes total orbit time with 27 minutes of eclipse. This maximum insolation of approximately 1.26 suns $\left(1\right.$ sun $\left.=1.37 \mathrm{~kW} / \mathrm{m}^{2}\right)$ is incidentally, the maximum output capability of the solar 
simulator lamps of the GTD system. The corresponding rate of energy crossing the aperture plane of the receiver during the simulated sun period is approximately 12.6 $\mathrm{kW}$.

The nominal operating speed of the GTD engine's turboalternator work-producing shaft is $56 \mathrm{k}$ RPM, which yields a working fluid mass flow rate of approximately $0.3541 \mathrm{lb}_{\mathrm{m}} / \mathrm{s}(161 \mathrm{~g} / \mathrm{s})$. A map of TAC speed versus mass flow rate is provided by Shaltens and Mason, ${ }^{14}$ from which a linear curve fit performed by the present authors is given by

$$
\dot{m}=0.0629+5.2 \times 10^{-6} \omega
$$

where $\omega$ is the TAC speed in RPM and $m$ is the working fluid mass flow rate in $1 \mathrm{~b}_{\mathrm{m}} / \mathrm{s}$.

The representative results pertain to 7 "test point" conditions obtained during November 1996 for the socalled "hybrid" configuration of the GTD system. Test points 3-5 represent operations to achieve balanced orbit conditions and test points 6-9 represent operations to achieve steady-state conditions. Test points 1 and 2 , in which some technical problems were encountered, were obtained during October 1996.

\section{Solar Receiver Energy Balance}

An important consideration in the numerical prediction of the solar receiver's thermal performance is the instantaneous overall energy balance. This is done to account for every unit of energy crossing the aperture plane per unit time. Fig. 4 is a plot of the solar receiver's energy budget up to test point 3 (first balanced orbit) conditions. The profile for the rate of

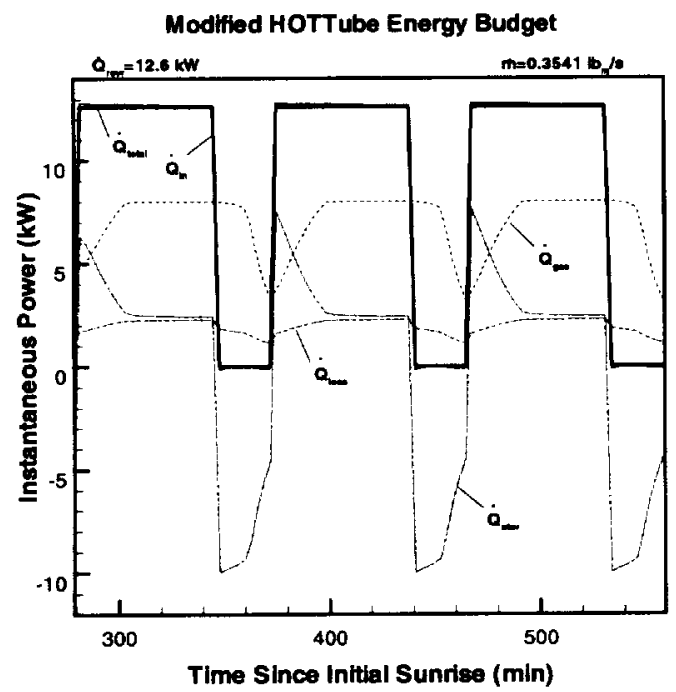

Fig. 4 Receiver energy balance up to test point 3 conditions. energy crossing the aperture plane (labeled " $\dot{Q}_{\text {in }}$ ") resembles a square pulse function, which illustrates the switching nature of consecutive sun periods and eclipse periods. If the receiver is truly balanced, then the sum (labeled " $\dot{Q}_{\text {total }}$ ") of the rate of energy extracted by the gas (labeled " $\dot{Q}_{\text {gas }}$ "), rate of energy lost by reradiation through the aperture and rate of energy lost through the receiver shell (labeled " $\dot{Q}_{\text {loss }}$ "), and rate of energy stored inside the receiver (labeled " $\dot{Q}_{\text {stor }}$ ") should also follow this square pulse function. This is indeed the case, as shown in Fig. 4, with a maximum error of less than 3 percent. This small error is primarily due to the receiver shell heat loss approximation.

\section{Temperature and Melt Fraction Predictions}

Fig. 5 shows the temporal progression of maximum canister outer surface temperature, average canister outer surface temperature, and receiver gas exit temperature from startup to 21 orbit cycles. The receiver heat input is fixed at $12.6 \mathrm{~kW}$ and the TAC speed varies from zero at startup to 56k RPM (up to orbit 12) to 58k RPM (orbits 13-21).

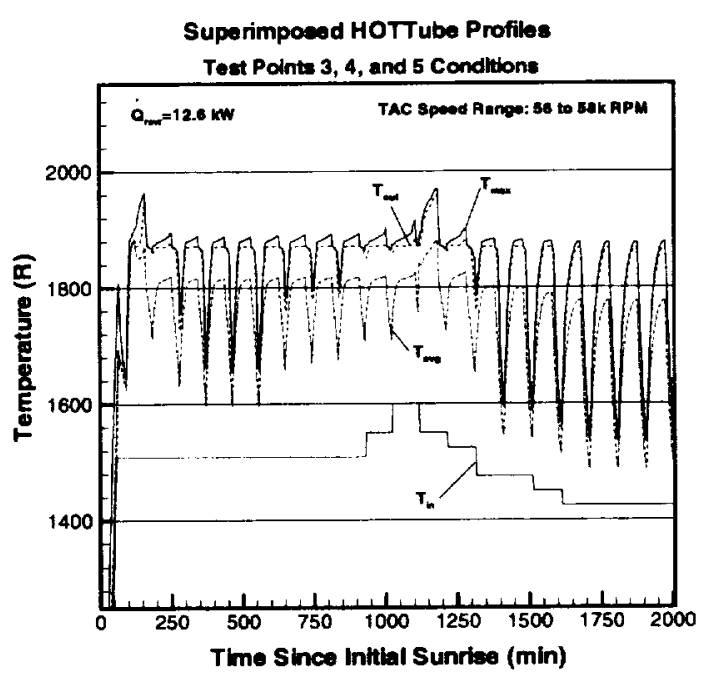

Fig. 5 Numerical prediction of maximum canister temperature, average canister temperature, and receiver gas exit temperature over 21 orbit cycles. 


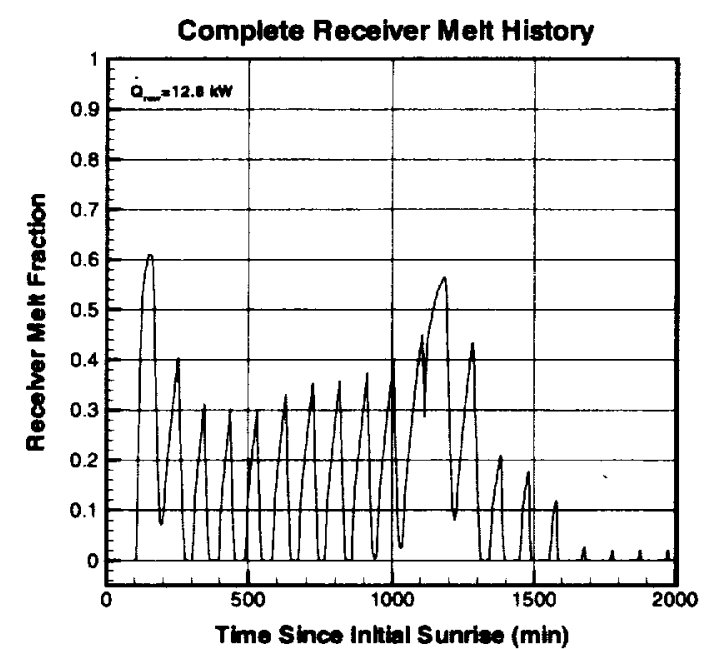

Fig. 6 Numerical prediction of the fraction of PCM in the liquid phase over 21 orbit cycles.

The transient operation for the orbital simulations is detailed as follows:

1) the startup mass flow rate is fixed at $0.005 \mathrm{lb}_{\mathrm{m}} / \mathrm{s}$ $(2.3 \mathrm{~g} / \mathrm{s})$ until the maximum canister temperature reaches $1900 \mathrm{R}(1056 \mathrm{~K})$, after which it is increased to $0.3541 \mathrm{lb}_{\mathrm{m}} / \mathrm{s}(161 \mathrm{~g} / \mathrm{s}$ ) (this occurs during the $2^{\text {nd }}$ cycle); faster heatup of the receiver is effected as a result

2) also during startup, the receiver gas exit temperature is fed back to the receiver inlet until the receiver inlet reaches $1508 \mathrm{R}(838 \mathrm{~K})$, which is accomplished during the $1^{\text {st }}$ cycle; this is an expedient computational scheme that advances the numerical solution to the point where higher fidelity modeling can be initiated

3) after the balanced orbit for test point 3 is reached on orbit 6 , the sun period is changed from $66 \mathrm{~min}$ to $72 \mathrm{~min}$ for orbits $7-9$; after the test point 4 balanced orbit is reached on orbit 9 , the sun period is further increased to 78,81 , and $84 \mathrm{~min}$ for orbits 10,11 , and 12 , respectively; the receiver inlet temperature is also increased to 1550,1600 , and $1550 \mathrm{R}$ for obits 10,11 , and 12 , respectively; these changes are done to effect an increase in the amount of PCM in the liquid phase

4) on orbits 13-21, the mass flow rate is increased to $0.3645 \mathrm{lb}_{\mathrm{m}} / \mathrm{s} \quad(165 \mathrm{~g} / \mathrm{s})$; the receiver inlet temperature is also sequentially decreased to 1525 , 1475,1450 , and $1425 R$ for orbits 13-16, respectively; the receiver inlet temperature remains fixed at $1425 \mathrm{R}$ for orbits $17-21$; these changes are performed to effect increased removal of energy from the receiver
For the numerical predictions, a balanced orbit is declared when the difference between all calculated temperatures is less than $2 \mathrm{R}(1.1 \mathrm{~K})$ between successive sunrise and sunset conditions.

It is further observed from Fig. 5 that over most of the orbit cycles

$$
\mathbf{T}_{\max }>\mathrm{T}_{\text {out }}>\mathrm{T}_{\text {avg }}
$$

which is also observed in the experimental data (next section). It is also observed that the maximum receiver exit temperature of $1958 \mathrm{R}(1088 \mathrm{~K})$, which is reached on the orbit 13 sunset, is within $0.2 \%$ of the experimental value of $1962 \mathrm{R}(1090 \mathrm{~K})$.

The corresponding fraction of receiver PCM in the liquid phase is illustrated in Fig. 6. Recall that the melting point of $\mathrm{LiF}-\mathrm{CaF}_{2}$ is $1873 \mathrm{R}(1040 \mathrm{~K})$ and its latent heat of fusion is $340 \mathrm{Btu} / \mathrm{b}_{\mathrm{m}}(789 \mathrm{~kJ} / \mathrm{kg})$. For the GTD solar heat receiver, the total mass of PCM is 53 $\mathrm{lb}_{\mathrm{m}}(24 \mathrm{~kg})$ which corresponds to a maximum latent storage capacity of $18,020 \mathrm{Btu}(19 \mathrm{MJ}$ or $5.3 \mathrm{~kW} \mathrm{hr})$. It is observed that the maximum liquid fraction, which occurs on sunset for all representative cycles, reaches a maximum of 61 percent during the heatup phase, 30 percent for test point 3,36 percent for test point 4 , a 56 percent local maximum on orbit 12 , and 3 percent for test point 5 , which is just out of the two-phase regime.

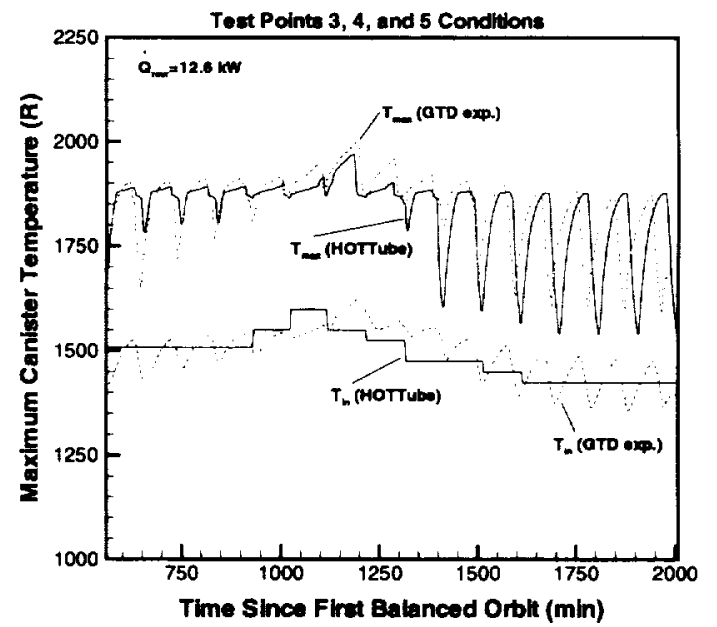

Fig. 7 Comparison of numerical and experimental results for the maximum canister surface temperature. 


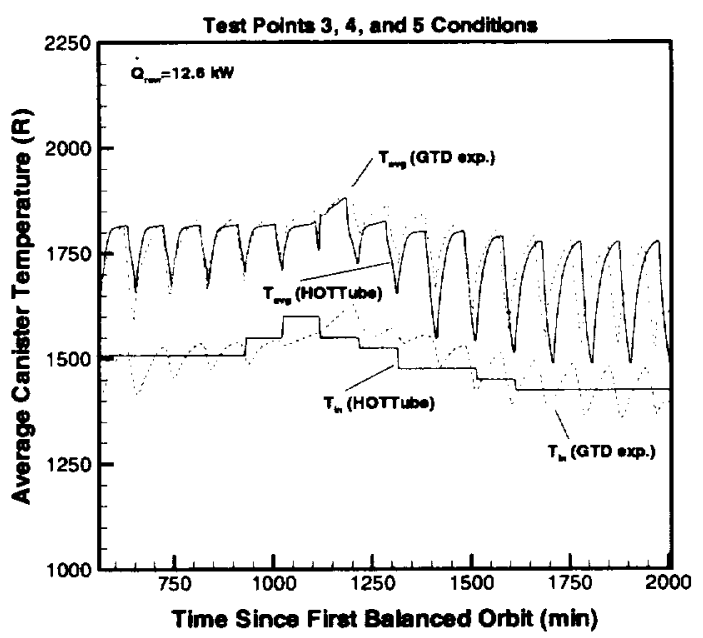

Fig. 8 Comparison of numerical and experimental results for the average canister surface temperature.

\section{Comparison of Numerical and Experimental Results}

In order to perform a direct comparison of modified HOTTube numerical predictions and GTD experimental results, the time scale for the experimental results had to be recalibrated to coincide with that used for the numerical predictions. This was done to mitigate any unmodeled dynamics associated with unexpected shutdowns and subsequent restarts, which occurred several times during the November 1996 test runs. As a result, comparisons are made from the first balanced orbit (test point 3 ).

Figs. 7 and 8 are comparisons of maximum and average canister outer surface temperatures, respectively, from test point 3 (TP 3 ) to orbit 21 . The first thing to note is that there is good qualitative agreement with regard to temperature slopes during both orbital sun periods and eclipse periods. It is also observed that the $\Delta \mathrm{T}$ between sunrise and eclipse is smaller for the numerical predictions during the first 4 cycles after TP 3 , indicating increased melting over that which occurs in the experiment. There are several possible explanations of this behavior: 1) the effective thermal mass in the model is less than the actual receiver, which would tend to cause overpredictions, 2) uncertainties in the dynamics which occur before reaching TP 3 balanced orbit conditions, and 3) differences in the receiver gas inlet profile. As the simulation progresses further into the latent regime (between 5 and 8 orbits beyond TP 3 ), this $\Delta T$ is reduced, as expected. Finally, the remaining orbits beyond TP 3 , indicate operation back into the subcooled regime, which is made possible by extended eclipse periods and higher TAC speed (mass flow rate). Another key observation is the significant difference (as high as $150 \mathrm{R}$ or $83 \mathrm{~K}$ ) between maximum and average canister temperatures. This is caused by the large variation in incident flux along the axis of the receiver tubes. However, in the latent regime, this difference is smaller, as expected.

A comparison of the receiver gas exit temperature is revealed in Fig. 9. Again, in comparison, the temperature slopes appear qualitatively similar throughout all orbit cycles beyond TP 3 . However, larger differences between sunrise and sunset temperatures are observed, particularly in the latter orbits. This appears to be caused by apparent high sensitivity to changes in receiver inlet gas temperature. This sensitivity appears to diminish in the latent regime, as expected, since the heat transfer characteristics would approach that of a tube with isothermal boundary conditions. As a result, the receiver gas temperature would approach this isothermal condition asymptotically as the gas approached the receiver exit.

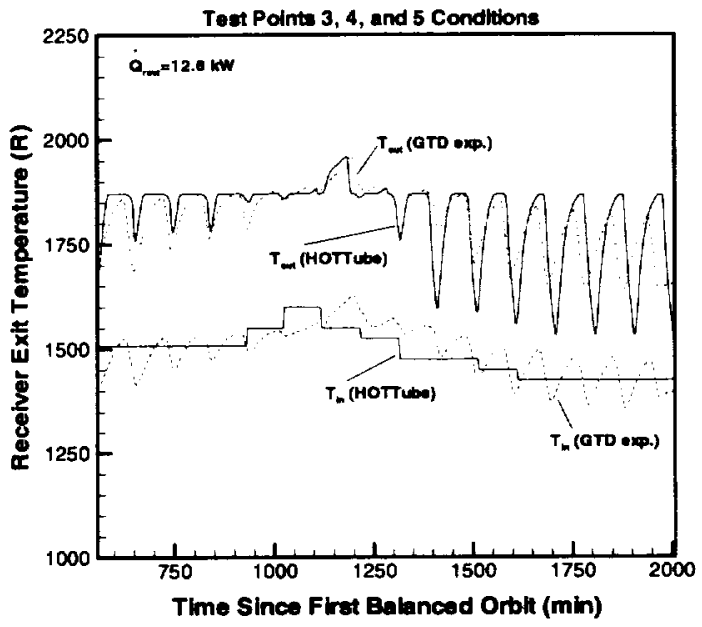

Fig. 9 Comparison of numerical and experimental results for the receiver gas exit temperature. 
Table 1. Comparison of steady-state test point performance of the GTD hybrid system configuration.

\begin{tabular}{|c|c|c|c|c|c|c|c|c|}
\hline & \multicolumn{2}{|c|}{ TP \#6 } & \multicolumn{2}{|c|}{ TP \#7 } & \multicolumn{2}{|c|}{ TP \#8 } & \multicolumn{2}{|c|}{ TP \#9 } \\
\hline & GTD exp & HOTTube & GTD exp & HOTTube & GTD ex & HOTTube & GTD exp. & HOTTube \\
\hline $\begin{array}{l}\text { RCVR heat input, } k W \\
\text { TAC speed, RPM }\end{array}$ & \multicolumn{2}{|c|}{$\begin{array}{c}7.01 \\
52,000\end{array}$} & \multicolumn{2}{|c|}{$\begin{array}{c}6.79 \\
48,000\end{array}$} & \multicolumn{2}{|c|}{$\begin{array}{c}8.17 \\
52,000\end{array}$} & \multicolumn{2}{|c|}{$\begin{array}{c}9.36 \\
52,000\end{array}$} \\
\hline RCVR exit temp, $R$ & 1661 & 1665 & 1735 & 1733 & 1795 & 1794 & 1934 & 1932 \\
\hline Gas heat input, $\mathrm{kW}$ & 5.78 & 5.60 & 5.32 & 5.13 & 6.50 & 6.21 & 7.10 & 6.68 \\
\hline RCVR losses, kW & 1.23 & 1.36 & 1.47 & 1.57 & 1.67 & 1.81 & 2.26 & 2.40 \\
\hline
\end{tabular}

Table 1 is a comparison of the solar heat receiver thermal performance for the steady-state test points (test points 6-9). It should be noted that test points 6-8 are in the sensible regime and test point 9 is in the latent regime. These comparisons are shown at reduced power levels (receiver heat input) and reduced TAC speeds (mass flow rates) as compared with test points 3 5. A steady-state test point is declared when all temperature transients are within less than $5 \mathrm{R} / \mathrm{hr}(2.8$ $\mathrm{K} / \mathrm{hr}$ ). As shown in the table, quantitative agreement is very good for all test points represented. The maximum difference in receiver gas exit temperature, which occurs for test point 6 , is $4 \mathrm{R}(2.2 \mathrm{~K})$, which results in a maximum error (over all test points) of less than 0.3 percent. Similarly, the maximum error in receiver gas heat input, which occurs for test point 9 , is less than 6 percent. Finally, the maximum error in receiver losses, which occurs for test point 6 , is less than 11 percent. Also observe that while the HOTTube numerical results underpredict the receiver gas exit temperature (except test point 6) and gas heat input, the receiver losses are overpredicted.

\section{Conclusions}

A physical and numerical model of the solar heat receiver component of NASA Lewis Research Center's Solar Dynamic (SD) Ground Test Demonstration (GTD) project has been developed. Numerical and experimental results are compared for balanced orbit and steady-state modes, and in both subcooled and latent (two-phase) regimes. Results show that while maximum and average canister outer surface temperatures are relatively insensitive to changes in receiver gas inlet temperatures, receiver gas exit temperatures are very sensitive to changes in receiver gas inlet temperatures, particularly for operation in the subcooled regime. HOTTube predictions also show very good agreement with GTD experimental data for subcooled and latent steady-state modes.

\section{Acknowledgment}

The financial support to Howard University from the NASA Lewis Research Center under grant number NAG-1907 is gratefully acknowledged.

\section{References}

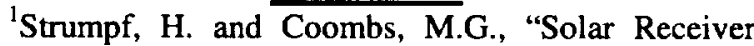
Experiment for the Hybrid Space Station Brayton Engine," Proceedings of the ASME Solar Energy Division Conference, San Diego, CA, 1988.

${ }^{2}$ Sedgwick, L.M., "Solar Dynamic Heat Receiver Technology Design Analysis Report," Boeing Report D180-29711-1, 1988.

${ }^{3}$ Wichner, R.P., Solomon, A.D., Drake, J.B., and Williams, P.T., "Thermal Analysis of Heat Storage Canisters for a Solar Dynamic Space Power System," ORNL TM - 10665, 1988.

${ }^{4}$ Wilson, D.G. and Flanery, R.E., "Modeling Cyclic Melting and Freezing in a Hollow Metal Canister," ORNL TM - 6497, 1988.

${ }^{5}$ Kerslake, T.W. and Ibrahim, M.B., "TwoDimensional Model of a Space Station Freedom Thermal Energy Storage Canister," NASA TM 103124 and Proceedings of the 25th Intersociety Energy Conversion Engineering Conference, Reno, NV, 1990.

'Drake, J.B., "Modeling Convective Marangoni Flows with Void Movement in the Presence of SolidLiquid Phase Change," ORNL TM - 6516, 1990.

${ }^{7}$ Hirt, C.W. and Nichols, B.D., "Volume of Fluid (VOF) Method for the Dynamics of Free Boundaries," Journal of Computational Physics, Vol. 39, 1981, pp. 201-225.

${ }^{8}$ Kerslake, T.W., "Experiments with Phase Change Thermal Energy Storage Canisters for Space Station Freedom," NASA TM 104427 and Proceedings of the 26th Intersociety Energy Conversion Engineering Conference, Boston, MA, 1991.

${ }^{9}$ Strumpf, H., Avanessian, V., and Ghafourian, R., "Design Analysis and Life Prediction for the Brayton Engine Solar Receiver for the Space Station Freedom Solar Dynamic Option," Proceedings of the 26th Intersociety Energy Conversion Engineering Conference, Boston, MA, 1991. 
${ }^{10}$ Strumpf, H., Avanessian, V., and Ghafourian, R., "Design Analysis and Containment Canister Life Prediction for a Brayton Engine Solar Receiver for Space Station," ASME Journal of Solar Energy Engineering, Vol. 116, 1994, pp. 142-147.

${ }^{11}$ Sedgwick, L.M., "Advanced Development Receiver Thermal Vacuum Tests with Cold Wall," NASA Contractor Report 187092, 1991.

${ }^{12}$ Skarda, J.R.L., "Thermal Modeling with Solid/Liquid Phase Change of the Thermal Energy Storage Experiment," NASA TM 103770, 1991.

${ }^{13}$ Namkoong, D., Jacqmin, D., and Szaniszlo, A., "Effect of Microgravity on Material Undergoing Melting and Freezing - The TES Experiment," Proceedings of the AIAA 33rd Aerospace Sciences Meeting and Exhibit, Reno, NV, 1995.

${ }^{14}$ Shaltens, R.K. and Mason, L.S., "Early Results from Solar Dynamic Space Power System Testing," AIAA Journal of Propulsion and Power, Vol. 12, No. 5, 1996, pp. 852-858.

${ }^{15}$ Jeffries, K.S. (ed.), "Solar Dynamic Power System Development for Space Station Freedom," NASA Reference Publication 1310, July 1993.

${ }^{16}$ Ensworth, C., McKissock, D., and Mason, L., “Comparison of CCEP with GTD Test Data," Internal Memorandum, Update \#3, August 1996. 


\begin{tabular}{|c|c|c|c|c|}
\hline \multicolumn{3}{|c|}{ REPORT DOCUMENTATION PAGE } & \multicolumn{2}{|r|}{$\begin{array}{l}\text { Form Approved } \\
\text { OMB No. 0704-0188 }\end{array}$} \\
\hline \multicolumn{5}{|c|}{ 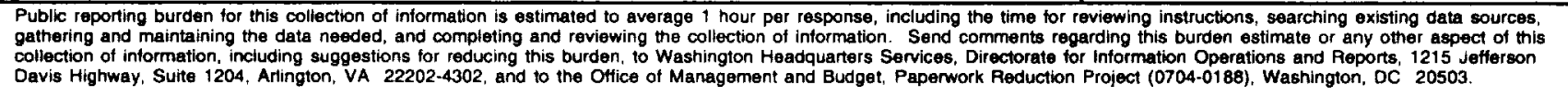 } \\
\hline 1. AGENCY USE ONLY (Leave blank) & $\begin{array}{r}\text { 2. REPORT DATE } \\
\text { June } 1997\end{array}$ & \multicolumn{3}{|c|}{ 3. REPORT TYPE AND DATES COVERED } \\
\hline \multicolumn{3}{|c|}{$\begin{array}{l}\text { 4. TITLE AND SUBTITLE } \\
\text { Modeling Cyclic Phase Change and Energy Storage in Solar Heat Receivers }\end{array}$} & \multicolumn{2}{|c|}{ 5. FUNDING NUMBERS } \\
\hline \multicolumn{3}{|l|}{ 6. AUTHOR(S) } & \multicolumn{2}{|c|}{ WU $-547-10-41$} \\
\hline \multicolumn{3}{|c|}{$\begin{array}{l}\text { 7. PERFOAMING OAGANIZATION NAME(S) AND ADDRESS(ES) } \\
\text { National Aeronautics and Space Administration } \\
\text { Lewis Research Center } \\
\text { Cleveland, Ohio } 44135-3191\end{array}$} & \multicolumn{2}{|c|}{$\begin{array}{l}\text { 8. PERFORMING ORGANIZATION } \\
\text { REPORT NUMBER }\end{array}$} \\
\hline \multicolumn{3}{|c|}{ 9. SPONSORING/MONITORING AGENCY NAME(S) AND ADDRESS(ES) } & \multicolumn{2}{|c|}{$\begin{array}{l}\text { 10. SPONSORING/MONITORING } \\
\text { AGENCY REPORT NUMBER } \\
\text { NASA TM-107487 } \\
\text { ALAA-97-2452 }\end{array}$} \\
\hline \multicolumn{5}{|c|}{$\begin{array}{l}\text { 11. SUPPLEMENTAAY NOTES } \\
\text { Prepared for the 32nd Thermophysics Conference sponsored by the American Institute of Aeronautics and Astronautics, Allanta, Georgia, } \\
\text { June 23-25, 1997. Carsie A. Hall, III, Emmanuel K. Glakpe, and Joseph N. Cannon, School of Engineering, Howard University, } \\
\text { Washington, DC 20059; Thomas W. Kerslake, NASA Lewis Research Center. Responsible person, Thomas W. Kerslake, organization } \\
\text { code } 6920,(216) 433-5373 \text {. }\end{array}$} \\
\hline \multicolumn{3}{|c|}{$\begin{array}{l}\text { 12a. DISTRIBUTIONAAVAILABILITY STATEMENT } \\
\text { Unclassified - Unlimited } \\
\text { Subject Category } 20 \\
\text { This publication is available from the NASA Center for AeroSpace Information, (301) 621-0390. }\end{array}$} & \multicolumn{2}{|c|}{ 12b. DISTRIBUTION CODE } \\
\hline \multicolumn{5}{|c|}{$\begin{array}{l}\text { Numerical results pertaining to cyclic melting and freezing of an encapsulated phase change material (PCM), integrated } \\
\text { into a solar heat receiver, have been reported. The cyclic nature of the present melt/freeze problem is relevant to latent heat } \\
\text { thermal energy storage (LHTES) systems used to power solar Brayton engines in microgravity environments. Specifically, } \\
\text { a physical and numerical model of the solar heat receiver component of NASA Lewis Research Center's Ground Test } \\
\text { Demonstration (GTD) project was developed and results compared with available experimental data. Multi-conjugate } \\
\text { effects such as the convective fluid flow of a low-Prandtl-number fluid, coupled with thermal conduction in the phase } \\
\text { change material, containment tube and working fluid conduit were accounted for in the model. A single-band thermal } \\
\text { radiation model was also included to quantify reradiative energy exchange inside the receiver and losses through the } \\
\text { aperture. The eutectic LiF-CaF } 2 \text { was used as the phase change material (PCM) and a mixture of He/Xe was used as the } \\
\text { working fluid coolant. A modified version of the computer code HOTTube was used to generate results for comparisons } \\
\text { with GTD data for both the subcooled and two-phase regimes. While qualitative trends were in close agreement for the } \\
\text { balanced orbit modes, excellent quantitative agreement was observed for steady-state modes. }\end{array}$} \\
\hline \multirow{2}{*}{\multicolumn{3}{|c|}{$\begin{array}{l}\text { 14. SUBJECT TERMS } \\
\text { Phase change materials; Heat storage; Solar dynamic power systems; } \\
\text { Molten salts; Solar energy; Space stations }\end{array}$}} & & $\begin{array}{c}\text { 15. NUMBER OF PAGES } \\
13\end{array}$ \\
\hline & & & & $\begin{array}{r}\text { 16. PRICE CODE } \\
\text { A03 }\end{array}$ \\
\hline $\begin{array}{l}\text { 17. SECURITY CLASSIFICATION } \\
\text { OF REPORT } \\
\text { Unclassified }\end{array}$ & $\begin{array}{l}\text { 18. SECURITY CLASSIFICATION } \\
\text { OF THIS PAGE } \\
\text { Unclassified }\end{array}$ & $\begin{array}{l}\text { 19. SECURITY CLASSIFICAT } \\
\text { OF ABSTRACT } \\
\text { Unclassified }\end{array}$ & & 20. LIMITATION OF ABSTRACT \\
\hline
\end{tabular}

